FEDERAL RESERVE BANK OF SAN FRANCISCO

WORKING PAPER SERIES

\title{
The Rising Cost of Climate Change: Evidence from the Bond Market
}

\author{
Michael D. Bauer \\ Universität Hamburg and CESifo \\ Glenn D. Rudebusch \\ Federal Reserve Bank of San Francisco \\ June 2021 \\ Working Paper 2020-25 \\ https://www.frbsf.org/economic-research/publications/working-papers/2020/25/
}

\section{Suggested citation:}

Bauer, Michael D., Glenn D. Rudebusch. 2021. "The Rising Cost of Climate Change: Evidence from the Bond Market," Federal Reserve Bank of San Francisco Working Paper 2020-25. https://doi.org/10.24148/wp2020-25

The views in this paper are solely the responsibility of the authors and should not be interpreted as reflecting the views of the Federal Reserve Bank of San Francisco or the Board of Governors of the Federal Reserve System. 


\title{
The Rising Cost of Climate Change: Evidence from the Bond Market*
}

\author{
Michael D. Bauer \\ Universität Hamburg and CESifo \\ Glenn D. Rudebusch \\ Federal Reserve Bank of San Francisco
}

June 28, 2021

\begin{abstract}
Social discount rates (SDRs) are crucial for evaluating the costs of climate change. We show that the fundamental anchor for market-based SDRs is the equilibrium or steady-state real interest rate. Empirical interest rate models that allow for shifts in this equilibrium real rate find that it has declined notably since the 1990s, and this decline implies that the entire term structure of SDRs has shifted lower as well. Accounting for this new normal of persistently lower interest rates substantially boosts estimates of the social cost of carbon and supports a climate policy with stronger carbon mitigation strategies.
\end{abstract}

Keywords: social discount rate, cost of carbon, natural rate of interest, r-star JEL Classifications: E43, E44, Q54, H43

${ }^{*}$ We thank Lint Barrage, Moritz Drupp, Stephie Fried, Christian Gollier, Ivan Jaccard, Elmar Mertens, Gilbert Metcalf, Toan Phan, and Billy Pizer for helpful comments, and Sophia Friesenhahn for excellent research assistance. A supplemental appendix is available online at https://www.michaeldbauer.com/ files/sdr_appendix.pdf. The views in this paper are solely the responsibility of the authors and do not necessarily reflect those of others in the Federal Reserve System. 


\section{Introduction}

When economic costs and benefits are distributed over time, they must be discounted to produce comparable present values that can be assessed on an equal footing. Such discounting is essential for a cost-benefit analysis addressing climate change. Greenhouse gases - the cause of climate change - tend to dissipate extremely slowly; for example, a significant fraction of today's emissions of carbon dioxide will remain in the atmosphere for centuries warming the earth. Therefore, any carbon pollution creates climate hazards for many generations to come. The precise value of the discount rate is critically important for making such intergenerational assessments, given that the costs of pollution are distributed over a very long time span and the effect of discounting increases exponentially with time.

For assessing public policy actions, a comparison of inflation-adjusted costs and benefits at different horizons employs the social discount rate (SDR). For a cost-benefit analysis of climate change, which must span decades and centuries, there is a very large literature analyzing and debating the critical choice of an SDR in this context. One major divide in determining the appropriate SDR has been between prescriptive and descriptive approaches. The former derives a normative SDR based on ethical fundamentals, while the latter relies on observed financial market prices, which embed public preferences about intertemporal trade-offs. The SDRs based on the prescriptive approach have generally been lower than those based on the descriptive approach. A survey of academic experts on social discounting by Drupp et al. (2018) indicates that estimates of a purely prescriptive SDR tend to be about 2 percentage points lower than estimates of a purely descriptive SDR. This disparity has been a substantial impediment to reaching a consensus on the SDR to use for valuing future damages from climate change.

However, we argue that the situation has changed in recent decades as a shift in economic and financial fundamentals has resulted in a lower new normal for interest rates, which in turn implies a lower descriptive SDR. Specifically, there is extensive evidence that the equilibrium or steady-state real interest rate, commonly denoted as $r_{t}^{*}$, has fallen since the 1990s (e.g., Del Negro et al., 2017, Christensen and Rudebusch, 2019, and Bauer and Rudebusch, 2020 among many others). One key driver of this steady decline in real interest rates has been the dramatic demographic transition around the world. In many countries, a longer life expectancy and steady retirement age appear to have resulted in more aggregate saving for post-employment years and lower real interest rates. Other underlying economic drivers of the decline in $r_{t}^{*}$ likely include lower productivity growth, a fall in the price of capital goods, rising income inequality, and strong saving flows from China and other emerging market economies (Summers, 2014; Hamilton et al., 2016). These forces have tended to increase 
global savings and reduce desired investment and have in turn exerted downward pressure on the equilibrium real rate. Moreover, these various economic trends show no signs of reversing, so low interest rates are likely to persist.

The gradual reduction in $r_{t}^{*}$ in recent decades has profound implications for the economics of climate change that have generally gone unrecognized. In this paper, we use an asset pricing framework to show theoretically and empirically how the persistent, secular decline in interest rates is relevant for descriptive SDRs. Specifically, we find that current market-based SDRs - calculated using data on risk-free real interest rates and empirical asset pricing models - are much lower than just two or three decades ago and much closer to the low discount rates often obtained from using a prescriptive approach. Hence, a descriptive approach to the SDRs that incorporates current estimates of the level and dynamics of $r_{t}^{*}$ results in a substantially higher discounted present value of future damages from marginally more carbon emissions than in the past. In essence, we demonstrate that the lower new normal for interest rates in turn implies a higher new normal for the market-based present value of climate change damages.

Based on the insight that $r_{t}^{*}$ is a key element underlying descriptive social discounting, our paper makes three contributions to the literature on social discounting and cost-benefit analysis of climate change. First, from an asset pricing perspective, as in Bauer and Rudebusch (2020), we show that conceptually $r_{t}^{*}$ is the fundamental anchor for the whole range of SDRs across different time horizons - the term structure of discount rates. The central importance of $r_{t}^{*}$ reflects the fact that it acts as a level shift factor, so the entire term structure of SDRs moves with the equilibrium real interest rate. Long-term rates are driven by expectations of future short-term rates, and all expectations of future real short rates move one-for-one with shifts in $r_{t}^{*}$. Intuitively, the reason for this sensitivity is that $r_{t}^{*}$ corresponds to the long-run trend, that is, the permanent component of real interest rates. Therefore, while various factors affect real interest rates at different maturities and horizons, shifts in $r_{t}^{*}$ move SDRs at all maturities.

Next, we quantify the fall in $r_{t}^{*}$ in recent decades and its effect on the term structure of SDRs. Since government bonds generally have maturities of only 30 years or less - too short to derive SDRs at the very long horizons needed to discount climate change damages - we combine the available market data with empirical interest rate models to derive the requisite long-maturity SDRs. We obtain $r_{t}^{*}$ estimates and SDRs from three different time series models using either short- or long-term inflation-adjusted government bond yields. Our various specifications all indicate that $r_{t}^{*}$ estimates have declined about 1 to 2 percentage points since the 1990s, which is consistent with existing macro-finance estimates from the literature. We then use these interest rate models to quantify how the decline in $r_{t}^{*}$ in recent 
decades has pushed down the entire term structure of discount rates - even at very long horizons. Because we allow for a time-varying long-run trend in real interest rates, which accounts for permanent structural variation in the economy, our results differ from earlier studies that also translate interest rate models into SDRs but impose stationary interest rates and mean reversion to a constant $r^{*}$ (e.g., Newell and Pizer, 2003, Groom et al., 2007, Gollier et al., 2008, Hepburn et al., 2009, Freeman et al., 2015, and Freeman and Groom, 2016). Allowing for the possibility of persistent shifts in interest rates is important for estimating the term structure of SDRs. Our conclusion that all SDRs have shifted lower in recent decades also extends to risk-adjusted SDRs. These add a climate risk premium to risk-free SDRs and thus are likely to be influenced by movements in $r_{t}^{*}$ to the same extent. Furthermore, along with a downward shift in SDRs, we estimate the extent of the declining slope in the term structure of discount rates that is induced by persistent shifts in $r_{t}^{*}$. This provides empirical confirmation and quantification of the theoretical insights of Weitzman (1998, 2001).

Finally, we analyze the implications of a lower $r_{t}^{*}$ and a lower term structure of SDRs for assessments of the damages from climate change. Specifically, we determine how much the downward shift in the term structure of SDRs increases the social cost of carbon (SCC), which is the present value of all future damages from a marginal increase in carbon emissions. ${ }^{1}$ For this calculation, we use damage estimates from two new versions of the classic DICE model that was originally developed by William Nordhaus (Nordhaus, 2017). Given the long time lag of future climate damages, the term structure of discount rates plays a central role in determining the SCC. Across various empirical real interest specifications coupled with two alternative climate-economy models that capture the economic damages from greenhouse gas emissions, we estimate that the decline in $r_{t}^{*}$ and resulting downward shift in SDRs since the 1990s has caused the SCC to at least double in size.

Our empirical results on social discounting have broad policy relevance for a range of issues that require consideration of intergenerational discounting, including public projects on infrastructure, health care, and so forth. We focus on what is widely viewed as the most pressing policy challenge of this century: assessing the economic impacts of climate change and incorporating such assessments into public policies on climate change mitigation and adaptation. Our reading of the current financial environment-and the projected permanence of low real rates - is consistent with the use of SDRs in the range of 0.5 to $2 \%$, which is much lower than previous descriptive SDRs or current policy practice. In addition, our analysis bolsters the case for using a declining term structure of discount rates. Overall,

\footnotetext{
${ }^{1}$ Our approach to calculating the SCC is similar to that in Newell and Pizer (2003) and subsequent studies following their example (e.g., Freeman et al., 2015).
} 
our empirical results are more closely aligned with previous prescriptive discount rates, as in Stern (2007), which support stronger efforts toward climate change mitigation.

\section{The role of the equilibrium real rate in discounting}

In this section, we lay the conceptual groundwork for our analysis of SDRs. We introduce an asset-pricing framework for discounting, define key concepts, and show theoretically why the long-run trend in the real rate, $r_{t}^{*}$, is the fundamental underlying determinant of SDRs.

To understand the importance of social discounting, first consider a representative costbenefit example in climate change economics: a mitigation project that reduces the amount of carbon in the atmosphere (either by reduced emissions or removal and storage). The up-front costs of this project must be weighed against the future benefits of reducing the environmental and economic damages that result from global warming, such as debilitating temperature increases and extremes, rising sea levels, species extinction, and destructive weather events, among others. A significant fraction of greenhouse gas emissions remain in the atmosphere for many generations, so the benefits from their reduction accrue over the same time horizon. In order to evaluate these future benefits (which are adjusted for price inflation and expressed in real terms), it is necessary to discount them back to the present, so that the stream of future benefits over time is collapsed into a single number, their present value. The interest rates used for this discounting, the SDRs, are naturally the central determinant of the present value of these future benefits, with higher rates lowering the present value.

Formally, the present value at time $t$ of a future payoff $X_{t+n}$ is defined as

$$
P V_{t}=P_{t}^{(n)} E_{t}\left(X_{t+n}\right)
$$

where $E_{t}(\cdot)$ denotes expectations of the potentially uncertain future payoffs conditional on information at time $t$, and $P_{t}^{(n)}$ is the price of a real zero-coupon bond - a claim to one unit of consumption at future time $t+n .^{2}$ In the context of intergenerational discounting and present-value analysis, the bond price $P_{t}^{(n)}$ is also referred to as a social discount factor.

This definition of present value, based on standard asset pricing theory, assumes that the future payoffs $X_{t+n}$ are riskless, in the sense that they are either (i) certain and therefore known at time $t$, (ii) uncorrelated with future consumption growth and marginal utility of the representative agent, or, (iii) in case actual payoffs are risky, expressed as certainty-equivalent payoffs, which are appropriately risk-adjusted. The focus in our paper is on such riskless

\footnotetext{
${ }^{2}$ Here and in what follows, all quantities are real, i.e., expressed in term of aggregate consumption.
} 
discounting, and our goal is to estimate risk-free social discount rates based on observed government bond yields in financial markets. We do so because risk-free SDRs have long been the main benchmark for social discounting (e.g., Newell and Pizer, 2003, Groom et al., 2007, and Drupp et al., 2018). However, as many have argued, climate risk is an important consideration in social discounting and the economics of climate change, and we will return to this issue in Section 6.

Short-term and long-run SDRs are commonly defined as the continuously compounded yields corresponding to the discount factors $P_{t}^{(n)}$ for different horizons. To start with, the short-term real interest rate or SDR, $r_{t}$, corresponds to the log-return on a one-period bond, $r_{t}=-\log P_{t}^{(1)}$. Under the assumption of risk-neutrality - which up to convexity in longterm rates is identical to the strong expectations hypothesis - the $n$-period discount factor is related to expected future short-term interest rates by

$$
P_{t}^{(n)}=E_{t}\left[\exp \left(-\sum_{j=0}^{n-1} r_{t+j}\right)\right]
$$

The "certainty-equivalent discount rate" in the language of Weitzman (1998) is defined as the yield on a long-term zero-coupon bond,

$$
y_{t}^{(n)}=-\frac{1}{n} \log P_{t}^{(n)},
$$

which is the SDR in period $t$ relevant for discounting damages that occur in period $t+n$. Clearly, a single value for the SDR - constant across all horizons - is unlikely to be suitable for discounting all future costs and benefits. Instead, the appropriate discount rate for various costs and benefits will vary with the horizon of their realization, that is, on $n$. As a result there should be a term structure of discount rates for discounting future costs and benefits that takes into account their timing.

As is evident from equations (2) and (3), expectations of future values of the short-term real interest rate, $r_{t}$, are the key determinants of long-run discount factors and discount rates. The stochastic properties of $r_{t}$, and in particular its long-run mean, therefore assume central importance for the term structure of SDRs. Formally, we define the equilibrium real interest rate as the long-run mean of $r_{t}$, that is,

$$
r_{t}^{*}=\lim _{h \rightarrow \infty} E_{t} r_{t+h}
$$

Consequently, $r_{t}^{*}$ represents the real rate that prevails in the economy after all shocks have 
died out, and it corresponds exactly to the stochastic trend component of $r_{t}{ }^{3}$ As a matter of definition, we can decompose the real short rate into trend and non-trend components,

$$
r_{t}=r_{t}^{*}+\tilde{r}_{t}
$$

where the non-trend or "cyclical" component, $\tilde{r}_{t}$, is stationary wth a long-run mean of zero. Long-term discount rates are determined by expectations of future short-term discount rates,

$$
E_{t}\left(r_{t+h}\right)=r_{t}^{*}+E_{t}\left(\tilde{r}_{t+h}\right)
$$

How far these expectations deviate from $r_{t}^{*}$ depends on the size of the current cyclical deviation $\tilde{r}_{t}$ and its speed of mean reversion. Over the very long horizons relevant for discounting future climate change, expectations of future short-term discount rates will generally be close to $r_{t}^{*}$.

The key insight is that $r_{t}^{*}$ affects the full future path of expected rates equally, because it corresponds to the long-run mean or "endpoint" of real-rate expectations. As a result it also acts as a level factor that shifts the entire term structure of SDRs. To make this precise, first note that long-term discount rates are not equal to average expected future short-term rates due to the nonlinear relationship (3) between bond prices and yields. The resulting Jensen inequality or "convexity" effect underlies the insight of Weitzman $(1998,2001)$ that discount rates are decreasing with maturity in an environment of uncertainty. We can use equations (2), (3), and (6) to obtain the following expression for long-term discount rates:

$$
\begin{aligned}
y_{t}^{(n)} & =-\frac{1}{n} \log E_{t}\left[\exp \left(-\sum_{j=0}^{n-1} r_{t+j}\right)\right] \\
& =\frac{1}{n} \sum_{j=0}^{n-1} E_{t} r_{t+j}+z_{t}^{(n)}=r_{t}^{*}+\frac{1}{n} \sum_{j=0}^{n-1} E_{t} \tilde{r}_{t+j}+z_{t}^{(n)},
\end{aligned}
$$

where $z_{t}^{(n)}$ is a convexity term that is negative and declining with maturity $n{ }^{4}$ Shortterm discount rates are sensitive to near-term cyclical fluctuations in real rates, $\tilde{r}_{t}$, while long-term discount rates are pushed down by uncertainty about future interest rates - a "negative convexity" effect (Weitzman, 1998, 2001; Gollier, 2002). However, discount rates of all maturities vary one-for-one with the equilibrium real rate, $r_{t}^{*}$, which acts as a level

\footnotetext{
${ }^{3}$ This is the trend concept of Beveridge and Nelson (1981) assuming that $r_{t}$ contains no deterministic time trend. In general, $r_{t}^{*}$ is a martingale and specifically a random walk (without drift) when innovations $r_{t}^{*}-r_{t-1}^{*}$ are $i i d$, which we assume below.

${ }^{4}$ How quickly and to what limit $z_{t}^{(n)}$ declines as $n$ increases depends on the stochastic properties of $r_{t}$. If $r_{t}$ is conditionally Gaussian, so bond prices are log-normal, then $z_{t}^{(n)}=-\frac{1}{2 n} \operatorname{Var}_{t} \sum_{j=0}^{n-1} r_{t+j}$.
} 
factor for the term structure of SDRs. The Online Appendix formally derives this result in the context of a simple affine dynamic term structure model with a specification for the real rate that includes a time-varying $r_{t}^{*}$.

Despite the central importance of shifts in the long-run mean of $r_{t}$ for the term structure of interest rates, much of the literature on fixed income modeling and social discounting has assumed that this process is stationary (or $I(0)$ in time series terminology). Under this assumption, $r_{t}$ exhibits reversion to a fixed long-run mean, which is the constant equilibrium real rate, $r^{*}=E\left(r_{t}\right)$. This assumption of stationarity is, however, at odds with evidence that real interest rates have a slow-moving trend component - the equilibrium real rate - that has notably declined in recent decades (see Holston et al., 2017, Christensen and Rudebusch, 2019, and many others). Bauer and Rudebusch (2020) show that it is necessary to include a stochastic trend in the real rate process in order to fully capture the highly persistent component of interest rates and explain the dynamic behavior of bond risk premia. ${ }^{5}$ These findings suggest the assumption of a constant $r^{*}$ will be problematic.

Much research has examined the structural economic factors pushing down the equilibrium real rate in recent decades (e.g., Summers, 2014, Hamilton et al., 2016, and Del Negro et al., 2017). Various candidate explanations include slower trend productivity growth and new, less capital-intensive technologies, which can curtail investment demand; significant saving flows from China and other emerging market economies (the so-called global savings glut); greater income inequality that favors an increased propensity to save; and an aging population with significant saving demands remaining for retirement. Such underlying fundamental economic shifts appear to have boosted global saving, reduced investment demand, and, as a result, lowered the steady-state real interest rate. Examinations of the longer-run historical record generally find that demographic variables have the most reliable connection with real interest rates (Lunsford and West, 2019). Not surprisingly then, the link between the changing demographic structure of global economies and real interest rates has been the focus of recent theoretical and empirical work (e.g., Carvalho et al., 2016, and Gerlagh et al., 2017). Importantly, the various economic forces that have lowered the equilibrium real rate appear likely to persist. Demographic forces, for example, are expected to continue to exert downward pressure on real interest rates for many years to come (Gagnon et al., 2021). Furthermore, the global savings glut has proven to be a lasting phenomenon. More generally, the balance of saving and investment appears to have shifted in a persistent fashion, prompting Larry Summers to revive the term "secular stagnation" to describe this

\footnotetext{
${ }^{5}$ See the Online Appendix for existing evidence on the decline in the equilibrium real interest rate. This literature also shows that the persistent decline in nominal bond yields over the past quarter century is mainly attributable to a lower $r_{t}^{*}$, with falling inflation expectations and risk premia playing an ancillary role.
} 
new reality (Summers, 2014; Rachel and Summers, 2019). Overall, the structural shifts in the balance of supply and demand for aggregate savings and the downward trend in the equilibrium real rate are unlikely to be reversed in the foreseeable future.

Taken together, these theoretical considerations and the existing empirical evidence of a secular decline in $r_{t}^{*}$ suggest potentially important implications for social discount rates and the economics of climate change. In the next three sections, we investigate these issues using an empirical approach with two noteworthy features. First, we use empirical models, not to estimate a single SDR, but instead to account for the entire term structure of SDRs. In contrast to the deep disagreement about the overall level of the SDR, there is a greater consensus that the SDR term structure should decline with the length of the discounting horizon. ${ }^{6}$ However, the proper specification of a declining SDR term structure remains an open topic for research. Our results provide further support and quantify a downwardsloping SDR term structure from a finance perspective. Second, we allow for time variation in $r_{t}^{*}$. Given the compelling evidence for a secular shift in real interest rates, we relax the assumption of a constant mean and allow the long-run mean of the real interest rate to be potentially time-varying - a so-called shifting endpoint. In time series terminology, we allow for the real short rate to contain a stochastic trend (i.e., to be $I(1)) .{ }^{7}$ Our investigation will show the empirical importance of such a stochastic trend for the entire term structure of SDRs and for social discounting of climate damages. ${ }^{8}$

\section{$3 \quad$ Empirical interest rate models with time-varying $r_{t}^{*}$}

In this section, we estimate time series models for the one-period real interest rate, $r_{t}$, that incorporate a time-varying trend component, $r_{t}^{*}$, as the shifting endpoint for $r_{t}$. These empirical models allow us to quantify the implications of the decline in $r_{t}^{*}$ over the past few decades for the level and slope of the entire term structure of SDRs, $y_{t}^{(n)}$.

Our first model is a univariate unobserved-components (UC) model, similar in econometric structure to various empirical macroeconomic models including Watson (1986), Morley et al. (2003), Bauer and Rudebusch (2020), and others. This UC model completes the earlier

\footnotetext{
${ }^{6}$ See, for example, Weitzman (2001), Newell and Pizer (2003), and Cropper et al. (2014).

${ }^{7}$ The real rate process is $I(1)$ if the first difference, $r_{t}-r_{t-1}$, is covariance stationary. This includes the special case that $r_{t}$ itself is already stationary, or $I(0)$.

${ }^{8}$ This discussion has focused on the statistical properties of the real interest rate and their implications for the term structure of discount rates. It is straightforward to connect these back to the underlying economic determinants in a simple model. The Online Appendix demonstrates how changes in the trend growth rate of aggregate consumption translate into changes in the trend of the real interest rate. Therefore, any long-run structural economic change that shifts the trend component in consumption growth also gives rise to a trend component and a level factor in real interest rates.
} 
trend-cycle decomposition for the short-term SDR with specifications for each component:

$$
\begin{aligned}
& r_{t}=r_{t}^{*}+\tilde{r}_{t}, \\
& r_{t}^{*}=r_{t-1}^{*}+u_{t}, \quad u_{t} \sim N\left(0, \sigma_{u}^{2}\right) \\
& \tilde{r}_{t}=\phi \tilde{r}_{t-1}+v_{t}, \quad u_{t} \sim N\left(0, \sigma_{v}^{2}\right) .
\end{aligned}
$$

The innovations to the trend and cycle, $u_{t}$ and $v_{t}$, are each $i i d$ normal, and they are mutually uncorrelated. The key feature of this model is that the long-run mean of $r_{t}$ is allowed to vary over time - here, as a random walk. Alternative specifications for the stationary component, $\tilde{r}_{t}$, such as including additional lags, have little impact on our results.

The crucial difference between our UC model and previous empirical analyses is that we do not impose a constant $r^{*}$ as the relevant anchor for inferring long-run discount rates. For example, an influential early specification is the mean-reverting model by Newell and Pizer (2003) in which the long-run mean, $r^{*}$, is effectively the sample average of $r_{t}$ - an assumption used in subsequent follow-up research. ${ }^{9}$ By contrast, our analysis takes into account that $r_{t}^{*}$ may vary due to structural economic changes over the estimation sample and incorporates more nuanced and flexible interest rate dynamics.

To estimate the UC model, we cast it into a state-space form with $r_{t}^{*}$ and $\tilde{r}_{t}$ as unobserved state variables, (9) and (10) as transition equations, and (8) as the measurement equation. We use Bayesian estimation methods and employ uninformative prior distributions for all the parameters except $\sigma_{u}^{2}$, the innovation variance of $r_{t}^{*}$. To encourage a smooth trend $r_{t}^{*}$, we use a tight prior around a low value for this variance, similar to Del Negro et al. (2017) and Bauer and Rudebusch (2020). For estimation, we use a Markov chain Monte Carlo sampler. ${ }^{10}$ The Online Appendix reports additional estimation details as well as a sensitivity analysis of the smoothness of $r_{t}^{*}$, which demonstrates that a more diffuse prior on $\sigma_{u}^{2}$ also leads to large declines in the estimated $r_{t}^{*}$.

We use two different annual data series for the real interest rate, $r_{t}$, to estimate this model. The first is a one-year (ex-ante) real interest rate that is measured as the difference between the nominal one-year constant-maturity U.S. Treasury yield and inflation expectations over the next year. Inflation expectations are measured as the median of the Livingston survey expectations for inflation in the consumer price index (CPI). Our annual sample, consisting

\footnotetext{
${ }^{9}$ Newell and Pizer (2003) also estimate a random walk model, which imposes $r_{t}=r_{t}^{*}$ and implies that all movements in real interest rates are permanent.

${ }^{10}$ We draw the unobserved state variables using the simulation smoother of Durbin and Koopman (2002) and the parameters using standard Gibbs steps. We sample five separate chains from random starting values, each with 20,000 iterations, of which we discard the first half as a burn-in sample. Standard diagnostics indicate that the chains have converged to their stationary distribution, which is the joint posterior distribution of the model.
} 
of December observations of yields and survey expectations, starts in 1953 and ends in 2019. The second data series is a proxy for the 10-year real interest rate, which is a common choice in the related SDR literature. ${ }^{11}$ We use the 10-year Treasury yield and subtract a popular measure of long-run inflation expectations, the time-varying perceived inflation target rate (PTR) from the Federal Reserve's main macroeconomic model. ${ }^{12}$ This annual sample starts in 1968, reflecting data availability for PTR.

Figure 1: Estimates of equilibrium real interest rate, $r_{t}^{*}$
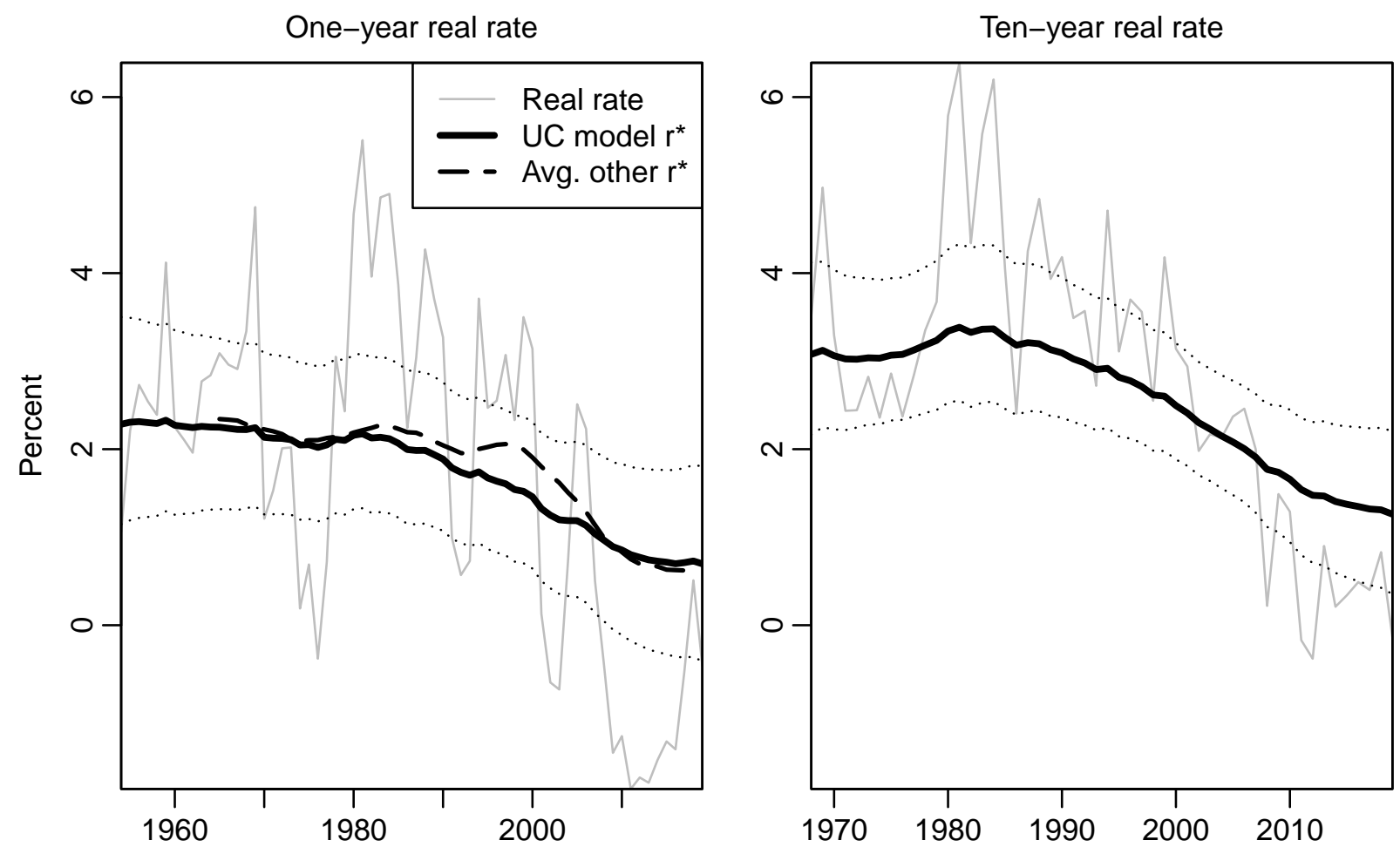

In the left panel, the gray thin line is the one-year real interest rate (one-year U.S. Treasury yield minus one-year inflation expectations) from 1954 to 2019. The dashed line shows the average of four existing macro-finance $r^{*}$ estimates as described in the Online Appendix. The right panel plots the ten-year real rate (ten-year Treasury yield minus long-term inflation expectations) from 1968 to 2019. In both cases, a $\mathrm{UC}$ model is estimated on the real rate series, and the resulting posterior mean estimate of $r_{t}^{*}$ is shown as a thick solid line, with thin dotted lines showing $68 \%$ Bayesian credibility intervals.

Figure 1 displays the one- and ten-year real interest rate series and the corresponding $r_{t}^{*}$ estimates from UC models fit to each series. For both data sets, the estimated trend component drifted sideways until the 1990s and then declined steadily for the last three

\footnotetext{
${ }^{11}$ See, for example, Newell and Pizer (2003); Groom et al. (2007); Freeman et al. (2015).

${ }^{12}$ See https://www.federalreserve.gov/econres/us-models-about.htm for more information.
} 
decades of the sample. The first line of Table 1 reports the estimated values for $r_{t}^{*}$ in 1990 and 2019 from the two empirical UC models. For the one-year real rate, the estimate of $r_{t}^{*}$ has declined by 1.2 percentage points over this period. For the ten-year real rate series, the level of the estimated trend is generally somewhat higher than for the one-year rate, and the decline in the trend component is also larger: 1.8 percentage points. A portion of this larger decline may be explained by a modest reduction in the term premium in long-term Treasury yields during this sample, as described by Bauer and Rudebusch (2020).

It is useful to compare these $r_{t}^{*}$ to previous estimates. The dashed line in the left panel of Figure 1 shows the average of four macro-finance estimates of $r_{t}^{*}$ from the empirical macrofinance literature. ${ }^{13}$ While based on a wide range of data samples and model specifications, these previous estimates all have declined substantially, and the figure shows that their average path in recent decades lines up closely with the estimates from our UC model. Therefore, our UC model results can be viewed as representative of the broader empirical macro-finance literature.

Our UC model captures shifts in the long-run mean by incorporating a stochastic trend, i.e., a unit root in the real interest rate. Models with stochastic trend components are commonly used in empirical macroeconomics due to their good forecast performance (Campbell and Perron, 1991). However, the unbounded forecast error variance resulting from the assumption of a random walk component can be unappealing - notably for asset pricing. To ensure the robustness of our results to this modeling choice, we also consider two alternative time series specifications for the real interest rate that capture shifts in the long-run mean without including a stochastic trend in the form of a random walk. These additional specifications modify the simple autoregressive (AR) model of Newell and Pizer (2003), who estimate an AR process for the deviation of $r_{t}$ from a constant mean. We follow this general approach of estimating AR models for $\tilde{r}_{t}$, but allow for a shifting long-run mean. ${ }^{14}$

Our first AR model accounts for the secular shift in the long-run mean SDR by allowing a structural break in $r^{*}$. Econometric tests suggest that there was a structural break sometime in the 1990s, and we use a 1991 break date. ${ }^{15}$ That is, we specify $r_{t}^{*}=\alpha+\beta D_{t}$ where $D_{t}$ is a dummy variable equal to zero until 1990 and one thereafter, then we estimate an $\operatorname{AR}(3)$ for $\tilde{r}_{t}=r_{t}-r_{t}^{*}$. The estimated shifts in the long-run mean are 2.2 and 1.9 percentage points

\footnotetext{
${ }^{13}$ These estimates are described and discussed in detail in Bauer and Rudebusch (2020). See also the Online Appendix.

${ }^{14}$ As in Newell and Pizer (2003), three lags of the interest rate are used — an AR(3) model — which captures the cyclical variation in interest rates. Also, in order to avoid negative SDRs, their models were estimated on the logarithm of the real interest rate, but as described in Section 4, we follow a more conventional shadow-rate approach to ensure non-negativity.

${ }^{15}$ Empirical support for this date is described in the Online Appendix. We also considered a data-based choice by searching for the break date that optimized the least-squares fit with similar results.
} 
Table 1: Estimates of $r_{t}^{*}$

\begin{tabular}{lccccccc}
\hline & \multicolumn{3}{c}{ One-year rate } & & \multicolumn{3}{c}{ Ten-year rate } \\
\cline { 2 - 3 } \cline { 8 - 9 } Model & 1990 & 2019 & Change & & 1990 & 2019 & Change \\
\hline UC model & 1.9 & 0.7 & -1.2 & & 3.1 & 1.3 & -1.8 \\
AR model, break & 2.8 & 0.5 & -2.2 & & 3.9 & 1.9 & -1.9 \\
AR model, learning & 2.8 & 1.3 & -1.5 & & 3.9 & 2.4 & -1.5 \\
\hline
\end{tabular}

Model-based estimates of $r_{t}^{*}$ using the one-year real rate (sample: 1954-2019) or the ten-year real rate (sample: 1968-2019). The time series models are described in the text.

in the short- and long-term interest rate samples, respectively, as shown in the second line of Table 1.

Our second AR model for $r_{t}$ accounts for the secular shift in the long-run mean by using an exponentially weighted moving average (EWMA) of $r_{t}$ as an estimate of $r_{t}^{*}$. An EWMA provides a widely-used and straightforward estimate of the trend component of a macroeconomic series (Cieslak and Povala, 2015; Bauer and Rudebusch, 2020). It is consistent with a simple adaptive learning mechanism in which agents learn about $r_{t}^{*}$ by weighting recent data more strongly than earlier observations. Following previous work that uses this learning model for interest rate dynamics (Piazzesi and Schneider, 2007; Orphanides and Wei, 2012), we estimate the model in two steps. First, we calculate the EWMA trend estimate as $r_{t}^{*}=\left(\sum_{j=0}^{t} \alpha^{j}\right)^{-1} \sum_{j=0}^{t} \alpha^{j} r_{t}$, where $\alpha$ determines the weight given to past data-higher $\alpha$ results in an effectively longer averaging window and a smoother estimate of $r_{t}^{*}$. Second, we estimate an AR model on the residuals $\tilde{r}_{t}$ using this trend. A constant-mean AR model, as in Newell and Pizer (2003), corresponds to the limiting case $\alpha=1$. We choose $\alpha=0.98$, which is in the usual range for empirical applications with annual data (Piazzesi and Schneider, 2007; Cieslak and Povala, 2015). Using this methodology, we estimate a decline in $r_{t}^{*}$ of 1.5 percentage points in both of our data samples, as shown in bottom line of Table 1. Allowing for a shift in $r^{*}$ in the context of a simple AR model, either using a deterministic break or adaptive learning, provides a useful robustness check on the SDR estimates from our UC model.

Our postwar sample of interest rates could be considered relatively short. By contrast, Newell and Pizer (2003) and Newell et al. (2020) have used a sample of long-term Treasury yields going back to $1798 .{ }^{16}$ The Online Appendix reports estimates of our SDR models

\footnotetext{
${ }^{16}$ Even longer historical samples that extend over several centuries show a long-run decline in real rates (Schmelzing, 2020), which also supports variation in $r_{t}^{*}$ over time.
} 
using these two centuries of data and shows that our qualitative conclusions are unaltered.

In sum, models that allow for shifts in the long-run mean of the real interest rate generally imply a substantial decline in this mean over the past three decades. This is true across a variety of model specifications - including a stochastic trend, a deterministic mean shift, or adaptive learning about the trend - as well as across different real interest rate series and sample periods.

\section{Estimates of the term structure of SDRs}

Following earlier research (e.g., Weitzman, 2001, Newell and Pizer, 2003, and Freeman et al., 2015), we obtain the term structure of discount rates implied by these time series models of the short-term real rate by using simulations and the expectations hypothesis. The essential difference with previous work, however, is that the long-run mean of $r_{t}$ is allowed to vary over time. We compare two different years, 1990 and 2019, to illustrate how the term structure of discount rates has shifted in recent decades. To calculate a model-implied term structure for each year, we use the following simulation approach:

1. For each year, $t=1990$ or 2019 , obtain the model-implied sampling distribution for the long-run mean $r_{t}^{*}$ and the model's parameters. For our UC model, these are Bayesian posterior distributions from the MCMC sampler, while for the other models these are normal distributions with means and standard deviations equal to the point estimates and standard errors of the parameters.

2. Simulate 50,000 paths of the real interest rate - each starting from a different draw from the sampling distribution for $r_{t}^{*}$ and the model parameters - extending out to a horizon of 400 years. Because the cyclical component $\tilde{r}_{t}$ captures short-run fluctuations in real rates that are ideally filtered out for inference about the term structure of SDRs, we start each simulated real-rate path at $\tilde{r}_{t}=0$, that is, at $r_{t}=r_{t}^{*}$.

3. Calculate the effective real short rate using a shadow-rate specification to ensure nonnegativity: $\hat{r}_{t}=\max \left(0, r_{t}\right)$.

4. Calculate a term structure of long-run discount rates from the simulated short rate paths using equations (2) and (3) and using $\hat{r}_{t}$ in place of $r_{t}$.

Two aspects of this canonical approach deserve elaboration. First, this procedure calculates the long-term rates implied by the dynamics of the short-term rate under the assumption of risk-neutrality - in asset pricing terminology, the risk-neutral probability measure is taken 
to be identical to the real-world probability measure. That is, there is no risk-adjustment of long-term rates, and up to convexity effects in long-term rates, the strong expectations hypothesis holds. This is the appropriate method to obtain risk-free social discount rates, which include neither a term premium nor a climate risk premium, and it has been used by many previous empirical studies in this literature. We will return to a discussion of climate risk below in Section 6 .

Second, we also follow previous work by ensuring the non-negativity of the implied SDRs. To this end, we use a shadow-rate construct that is common in nominal interest rate models to impose a zero lower bound, which is theoretically justified by the available arbitrage with zero-interest cash (Christensen and Rudebusch, 2015; Bauer and Rudebusch, 2016). ${ }^{17}$ For real interest rates, no such arbitrage argument can be made, and imposing a lower bound on real rates is rare in term structure models. Nevertheless, a non-negativity constraint is typical in empirical models of long-term SDRs for a number of reasons. First, historically, it appears that "negative [real] rates are unlikely to persist for long periods" (Gollier et al., 2008, p. 771). For example, long-term U.S. indexed-debt yields turned negative for the first time ever during the extraordinary circumstances of the Covid pandemic but turned positive in early 2021. Second, very long-term real discount rates are generally positive in expert surveys and in rare instances where financial markets give direct evidence of such rates. ${ }^{18}$ Third, conceptually, the imposition of the non-negativity constraint reflects the power of discounting, as even slightly negative long-term SDRs can produce exploding present values of future damages and imply an implausibly large willingness of the current generation to pay for reduced carbon emissions. For these and other reasons, model-based estimates of long-term SDRs are typically constrained to remain positive. We use the shadow-rate approach to ensure non-negative term structures of SDRs, which in our view is preferable over alternatives such as discarding simulated paths with real rates outside certain bounds (e.g., Freeman et al., 2015) or modeling and simulating the logarithm of the real rate (e.g., Newell and Pizer, 2003; Groom et al., 2007).

The non-negativity constraint is particularly appropriate for the UC model, which includes a random walk component to capture the persistent trend in real interest rates. This random walk component implies that uncertainty about the level of future yields is unbounded, so the bond convexity/Weitzman effect eventually dominates and pushes modelimplied rates into negative territory. Accordingly, in the absence of a non-negativity con-

\footnotetext{
${ }^{17}$ While recent years have shown that nominal rates can in practice dip into negative territory due to limits to this arbitrage, an effective lower bound slightly below zero is still likely to exist.

${ }^{18}$ In the survey of Drupp et al. (2018), none of the experts responded with a real interest rate or intergenerational SDR below zero (see their Table 1). Giglio et al. (2015) estimate positive real discount rates for very long maturities from housing data in the U.K. and Singapore.
} 
straint, the unbounded long-run variance causes interest rates to eventually diverge to minus infinity (Bauer and Rudebusch, 2020). Therefore, although we employ the parsimonious and popular random walk specification, it is useful to temper its more extreme implications in the limit and impose non-negativity.

Figure 2 shows the term structures of discount rates in 1990 and 2019 that are implied by our three different interest rate models and our two alternative interest rate data series. We plot these $y_{t}^{(n)}$ term structures for horizons from $n=1$ to $n=400$ years. Consistently, across all model and data variations, there is a notable shift downward shift in the term structures of SDRs over the past three decades. In each case, the decline in $r_{t}^{*}$ has pushed down the entire SDR term structure. Of course, the theoretical arguments in Section 2 imply that SDRs at all maturities shift with $r_{t}^{*}$, as changes in this anchor have a one-for-one effect on expectations of future values of $r_{t}$. But ultimately it is an empirical question as to how much short- and long-term rates have shifted, balancing changes in $r_{t}^{*}$ and other components such as the convexity in long-term rates. Our results show that, at the short end, the downward shift is broadly similar to the decline in $r_{t}^{*}$, while long-term SDRs move down by less, reflecting the moderating presence of the zero lower bound. Overall, the pronounced decline in the equilibrium real interest rate translates into a significant downward shift in discount rates at all horizons. This result is robust across our various model specifications and interest rate series.

Due to the decline in the long-run SDR anchor $r_{t}^{*}$, the non-negativity constraint has become more relevant in 2020 compared to 1990. This explains why long-term SDRs declined quite a bit less over this period than $r_{t}^{*}$ itself. As a result, relaxing this constraint-for example, by imposing a lower bound slightly below zero - would lead to an even more pronounced decline in the term structure of SDRs. In this sense, our estimates of the downward shift in discount rates, and of the resulting increase in the SCC discussed below, are conservative, because these shifts would be even larger without imposing a non-negativity constraint on SDRs.

In addition, all SDR term structures clearly decline with maturity - apart from an occasional small initial hump at short maturities. The substantial uncertainty about future short-term real rates translates into lower long-term rates due to the convexity of discount factors (Weitzman, 1998, 2001). Therefore, longer and longer maturity SDRs fall below the anchoring levels of $r_{t}^{*}$ (the dashed lines). The declining pattern starts earlier and is more pronounced for the UC model estimates, due to the presence of a stochastic trend and possible future variation in $r_{t}^{*}$ that adds to uncertainty about the future evolution of $r_{t}$. Our findings empirically quantify the view in the theoretical literature that the term structure of SDRs should be downward-sloping. For a range of different empirical specifications, we find 
Figure 2: Term structures of discount rates
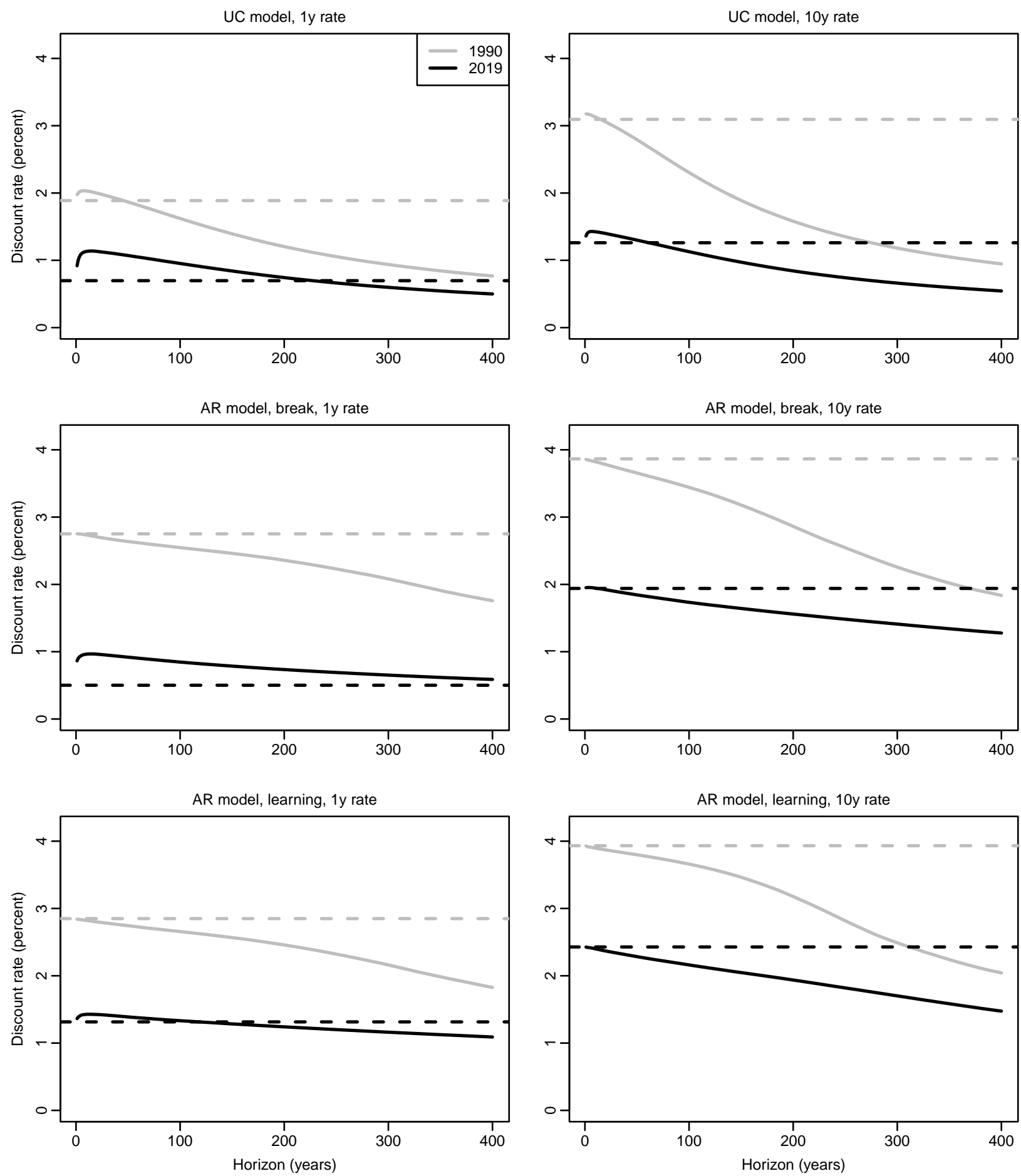

Term structures of discount rates (real yields) calculated using simulations from UC model (top row), an $\mathrm{AR}(3)$ model with a deterministic break in the mean (middle row), and an AR(3) model with exponential learning (bottom row). All long-run SDRs are obtained using simulations and a shadow-rate constraint for the real short rate that ensures non-negative rates. The gray term structure is based on the real rate and estimated $r_{t}^{*}$ in 1990, and the black term structure uses the values for 2019. The dashed lines show the model-based estimates of $r_{t}^{*}$ in those two years. 
that, unless SDRs start close to zero, they substantially decline with maturity typically by about 1 to 2 percentage points over the relevant horizons.

\section{$5 \quad$ A Shifting $r_{t}^{*}$ and the social cost of carbon}

One of the most pressing applications of social discounting is the valuation of longer-term climate change damages from greenhouse gas (GHG) emissions, which remain in the atmosphere for some time. Here, we show that the downward shift in the equilibrium real interest rate in recent decades, which pushed down the level of the entire term structure of discount rates, has important implications for assessing the economic costs of climate change.

The economic costs of climate change are often summarized by the social cost of carbon (SCC), that is, the discounted present value of the future damages caused by one additional ton of carbon dioxide $\left(\mathrm{CO}_{2}\right)$ emissions or equivalent GHG emissions (NAS (2017)). The calculation of the SCC requires (i) a time profile of the marginal future consumption damages caused by an increase in current emissions, and (ii) a term structure of social discount rates to assess the present value of those damages. Historically, the first item has been calculated with integrated assessment models (IAMs), which link changes in greenhouse gas concentrations to climate and economic outcomes (Greenstone et al., 2013). The IAM developed by William Nordhaus - the DICE model - has been widely used in previous research to assess the economic implications of changes in SDRs (e.g., Newell and Pizer, 2003; Groom et al., 2007; Freeman et al., 2015). To understand the effect of discounting on the SCC, we follow this literature by taking marginal damages as given - discounting them using past and current term structures of discount rates. In theory, the DICE model profile of marginal damages is endogenous to assumptions about interest rates, which, for example, affect the time paths of capital and output. However, changes in interest rates arguably have only second-order effects on future economic damages from climate change but first-order effects via discounting on the present value of these damages. Alternatively, our approach can be motivated by the analysis of van der Ploeg and Rezai (2019) who assume that private agents discount the future with the standard DICE parameters but the social planner sets carbon prices using a lower discount rate. This allows economy-wide discount rates within the DICE model to differ from the discount rates used to calculate the SCC from the model's climate damages.

For our calculations of the SCC, we use two new variants of the DICE model that modify the standard DICE-2016 model of Nordhaus (2017) to account for recent advances in climate science. One variant is the updated DICE model of Hänsel et al. (2020) which modifies the economic and climate modules and incorporates a "median expert view" regarding the 
parameters of the social welfare function. Notably, this model-which for simplicity we label as the "DICE-H" model - implies that under the optimal mitigation policies the global warming path is in line with the UN climate targets. The second variant is the updated DICE model proposed by Dietz et al. (2020), specifically their "DICE-FAIR-Geoffroy" model, which we term the "DICE-D" model. Dietz et al. (2020) argue that the DICE model and other IAMs in the economics literature are poorly specified relative to large-scale climate models and exhibit an excessively long lag between $\mathrm{CO}_{2}$ emissions and subsequent global warming. The DICE-D model incorporates a climate module arguably more consistent with the latest physical science representations, which results in a more accurate carbon cycle and reduced delay between emissions and warming.

The DICE-H and DICE-D models imply substantially different marginal damage profiles that largely span a wide range of views about the deleterious effects from higher GHG emissions. As we illustrate in the Online Appendix, the damage profile of DICE-D is steadily increasing over time, while the profile derived from DICE-H is hump-shaped. This divergence illustrates the substantial specification uncertainty about assessments of climate damages, as stressed by Pindyck (2013). The wide range of damage estimates exhibited by the DICE-H and DICE-D models allow us to examine the robustness of our conclusions about the effects of a lower $r_{t}^{*}$ on the social cost of carbon. ${ }^{19}$

To calculate the SCC we add up the stream of discounted damages over the next 400 years to get a present value of future damages. That is, we calculate the SCC for a certain base year $t$ as

$$
S C C_{t}=\sum_{n=0}^{400} P_{t}^{(n)} M D_{t+n}
$$

where $P_{t}^{(n)}=\exp \left(-n y_{t}^{(n)}\right)$ is the discount factor corresponding to the SDR with annual maturity $n$, and $M D_{t+n}$ is the estimate of marginal consumption damages in year $t+n$ from the model (see the Online Appendix for a detailed derivation). These marginal damages are the consumption loss, measured in constant U.S. dollars, from an additional metric ton of $\mathrm{CO}_{2}$ emissions in the base year $t$. We use the same path of marginal damages and discount them with the estimated SDR term structures for 1990 and 2019. For each damage profile (from either DICE-H or DICE-D) and for each SDR term structure model, we report an estimate of the SCC in each year. Our results focus only on the effect of changing discount rates and ignore other possible changes over the past three decades in the economy and the

\footnotetext{
${ }^{19}$ We thank Moritz Hänsel for providing us with the marginal damages calculated from DICE-D model. In the Online Appendix, we also report SCC calculations for the older DICE-94 model of Nordhaus (1994), which was used in Newell and Pizer (2003), and the newer DICE-2016 model discussed in Nordhaus (2017). These results are qualitatively similar to the ones shown in the paper.
} 
climate system.

Table 2: Estimates of the SCC (dollars per metric ton of $\mathrm{CO}_{2}$ )

\begin{tabular}{lcccc}
\hline Model & Change in $r_{t}^{*}$ & 1990 & 2019 & \% Change \\
\hline DICE-H, from Hänsel et al. (2020) & & & & \\
UC model, 1y rate & -1.2 & 218.8 & 396.7 & $81 \%$ \\
UC model, 10y rate & -1.8 & 127.5 & 340.4 & $167 \%$ \\
AR model, break, 1y rate & -2.2 & 107.8 & 422.4 & $292 \%$ \\
AR model, break, 10y rate & -1.9 & 64.2 & 188.1 & $193 \%$ \\
AR model, learning, 1y rate & -1.5 & 101.2 & 260.4 & $157 \%$ \\
AR model, learning, 10y rate & -1.5 & 58.9 & 137.9 & $134 \%$ \\
\hline DICE-D, from Dietz et al. (2020) & & & & \\
UC model, 1y rate & -1.2 & 387.6 & 963.1 & $149 \%$ \\
UC model, 10y rate & -1.8 & 193.8 & 800.7 & $313 \%$ \\
AR model, break, 1y rate & -2.2 & 61.3 & 886.0 & $1346 \%$ \\
AR model, break, 10y rate & -1.9 & 32.4 & 175.7 & $443 \%$ \\
AR model, learning, 1y rate & -1.5 & 54.9 & 300.5 & $447 \%$ \\
AR model, learning, 10y rate & -1.5 & 26.3 & 101.1 & $284 \%$ \\
\hline
\end{tabular}

Estimated social cost of carbon (SCC) for six empirical SDR models and two different marginal damage profiles. The change in each model-based $r_{t}^{*}$ estimate from 1990 to 2019 is shown in percentage points. The columns "1990" and "2019" show the SCC using the SDR term structures for 1990 and 2019 implied by each SDR time series model. The SCC is calculated in constant 2010 U.S. dollars, for the base year 2015, from the marginal consumption damages over 400 years resulting from one extra ton of $\mathrm{CO}_{2}$ emissions. Estimated damages are based on one of two models: (i) "DICE-H" (top panel) or (ii) "DICE-D" (lower panel).

Table 2 quantifies the change in the SCC from shifts in the slope and level of the term structure of discount rates for the six empirical SDR specifications described in Section 3. We first discuss the effects of declining SDRs and then turn to the downward shift caused by a lower $r_{t}^{*}$.

To understand the effects of a downward-sloping term structure of SDRs, it is helpful to first establish a constant-SDR point of reference. For a constant $2 \%$ discount rate, the DICE$\mathrm{H}$ model yields an SCC estimate of $\$ 157$, while DICE-D implies an SCC of $\$ 98$ (measured in constant 2010 U.S. dollars with a 2015 base year). For the UC model with the one-year real rate, $r_{t}^{*}$ in 1990 is actually quite close to $2 \%$, but the implied term structure of SDRs, shown as the gray line in the upper left panel of Figure 2, slowly falls from $2 \%$ to below $1 \%$ as the horizon increases. Relative to a constant $2 \%$ discount rate, the effect of this declining 
term structure is to push up the estimated SCC to $\$ 219$ for DICE-H and $\$ 388$ for DICED. That is, accounting for the declining shape of the SDR term structure - resulting from the presence of uncertainty and persistence in the time series of SDRs - has a pronounced effect on the estimated SCC. This effect is attenuated for the DICE-H model because of its hump-shaped marginal damage profile, which causes differences in long-run SDRs to have less impact than for DICE-D, where the damage profile steadily increases with the horizon.

For the AR models, the decline in the estimated term structures is more moderate than for the UC model (see Figure 2 and the discussion in Section 4). For the model with a deterministic break in the mean, estimated on the ten-year rate, $r_{t}^{*}$ in 2019 is also close to $2 \%$. The implied term structure declines more slowly and only to about $1.3 \%$. However, the value of the SCC still rises substantially compared to the constant-SDR case, to $\$ 188$ for DICE-H and to $\$ 176$ for DICE-D. Thus, the effects of a declining term structure are quantitatively large and robust across fundamentally different SDR model specifications.

We now turn to the effect on the SCC of a drop in $r_{t}^{*}$. The first column of Table 2 shows the percentage point change in the estimated equilibrium real rate from 1990 to 2019 for each SDR specification. The decline in $r_{t}^{*}$ pushes down the entire term structure of SDRs - as illustrated in Figure 2. For the UC model for the 1-year rate, the downward shift increases the SCC by $81 \%$, to about $\$ 397$, for DICE-H. Using DICE-D, the effect of shifting SDRs is more pronounced, increasing SCC by almost 150\%. The increases in the SCC are even more substantial for the other five SDR models because those models imply a larger decline in $r_{t}^{*}$, ranging from -1.5 to -2.2 percentage points. These secular shifts result in an increase in the SCC by 130 to $190 \%$ for DICE-H, and by 280 to $1350 \%$ for DICE-D. Again, the differences between the two climate-economy models reflect the different shapes of the marginal damage profile, with rising damages for DICE-D giving a much larger role to shifts in long-term discount rates. The relative magnitudes of the increases in the SCC are generally in line with the estimated declines in $r_{t}^{*}$. The level of $r_{t}^{*}$ is clearly a key determinant of the SDR term structure and the SCC.

Across our six different SDR models and the two climate-economy models, there are vast differences in the level of the estimated SCC. The wide range of estimates reflects the substantial model specification and estimation uncertainty that is typical in quantitative assessments of the damages from climate change (Greenstone et al., 2013). Our emphasis, however, is not on a specific numerical range for the level of the $S C C$, which would require a careful defense of the underlying IAM assumptions and damage estimates. Instead, the key result in Table 2 is that the SCC increases dramatically once we account for the secular shift in SDRs resulting from the decline in $r_{t}^{*}$. This result, the large increase in the SCC is 
remarkably robust across all specifications. ${ }^{20}$

To sum up, the drop in the equilibrium real rate over the past few decades has sizable economic implications for assessing the cost of climate damages. The lower discount rates that result from the decline in $r_{t}^{*}$ - the anchor of the SDR term structure - are accompanied by a declining term structure of SDRs. These necessarily lead to higher present values of future climate damages, and our estimates suggest that the decline in $r_{t}^{*}$ over the past few decades generally at least doubles the SCC.

\section{Implications for climate policy of a lower $r_{t}^{*}$}

The decline documented in the equilibrium real interest rate over the past three decades is relevant for a wide range of issues in economics and, especially, for economic policy. For monetary policy, the secular decline in $r_{t}^{*}$ implies a lower new normal for policy rates and a higher likelihood of hitting the zero lower bound, which requires new policy frameworks and tools (Bernanke, 2020). For fiscal policy, it suggests that public debt may have lower fiscal costs, potentially allowing for higher sustainable sovereign debt levels (Blanchard, 2019). A lower $r_{t}^{*}$ also has pronounced implications for climate policy arising from its effect on the level of discount rates and the social cost of carbon. In the United States, these implications have particular relevance given recent actions toward a reassessment of the SCC used by federal agencies in cost-benefit analyses. In January 2021, a U.S. federal Interagency Working Group (IWG) on the Social Cost of Greenhouse Gases was re-established, under the leadership of the Office of Management and Budget (OMB) and the Council of Economic Advisers (CEA), in order to ensure that federal SCC estimates were updated with the best available science. As stressed in Interagency Working Group on Social Cost of Greenhouse Gases (2021) (IWG$\mathrm{SC})$, the discounting assumptions underlying these estimates are a critical area for review and revision, and this section discusses the implications of our results for these assumptions.

Previous analyses of social discounting have generally taken one of two approaches: a normative/prescriptive approach that recommends an SDR that conforms to certain standards of optimality and fairness, or a positive/descriptive approach that recommends an SDR based on observed market valuations. The former approach, detailed in Gollier (2013), focuses on economic models, behavioral parameters, and normative judgments, and, depending on specific assumptions, can obtain quite small discount rates. A prominent example is

\footnotetext{
${ }^{20}$ Some DICE model variants, such as DICE-D and DICE-2016, incorporate assumptions that imply everincreasing marginal damages with the horizon. For low SDRs, this assumption raises issues of the boundedness of the SCC: If the SDR is lower than the growth rate of damages, the contribution of discounted damages does not decline with horizon. In these cases, truncating the horizon at 400 years provides a conservative estimate of the effect of a decline in $r_{t}^{*}$.
} 
the famous Stern (2007) Review, which assessed climate change damages using a normative SDR of approximately 1.4\%. By contrast, the descriptive approach, which is employed in this paper, is empirically based and infers SDRs from observed rates of return on capital and financial investments, which range from essentially risk-free Treasury bills to stock market indices. Prominent examples of a descriptive approach in climate change cost-benefit analysis include Newell and Pizer (2003) and the U.S. IWG efforts noted above. Specifically, in 2010, the IWG recommended using three different constant discount rates across the federal government to span a range of certainty-equivalent SDRs: $2.5 \%, 3 \%$, and $5 \%$ (IWG-SC). The $3 \%$ value was consistent with earlier guidance of the U.S. OMB based on real longer-term yields. ${ }^{21}$ The higher $5 \%$ was included to account for a risk compensation while the lower $2.5 \%$ was an attempt to account for a declining SDR term structure - we discuss both of these adjustments below.

The descriptive approach has generally resulted in higher discount rates than the prescriptive method. Furthermore, the use of a normative SDR in the Stern Review that was lower than typical descriptive SDRs was viewed as a critical failing by Nordhaus (2007): "The Review's unambiguous conclusions about the need for extreme immediate action will not survive the substitution of assumptions that are more consistent with today's marketplace real interest rates and savings rates" (p. 686). ${ }^{22}$ Similarly, Drupp et al. (2018) found that the SDRs recommended by experts depended on the relative weight given to normative versus positive concerns and that this dependence was so strong that a purely positive SDR would be 2 percentage points higher than a completely normative one.

Our empirical work brings descriptive SDRs into closer alignment with the typically low prescriptive SDRs from a normative analysis. Our descriptive SDRs are substantially lower than those in previous empirical work not simply because we account for recent low real interest rates but because we account for the decline in the equilibrium real rate, which anchors all discount rates. A useful way to frame this issue is to distinguish between cycles and trends in real interest rates. That is, although real interest rates have been historically low in recent years, the implications of this fact for discount rates over horizons of many decades and centuries depend crucially on the relative importance of a long-run trend versus

\footnotetext{
${ }^{21}$ U.S. Office of Management and Budget (2003) recommended that regulatory agencies estimate net benefits of public policies using two alternative real discount rates of $3 \%$ and $7 \%$. The higher rate reflects an estimate of the average before-tax rate of return to private capital in the U.S. economy - a broad measure that includes a compensation for risk as discussed below. The lower rate reflects "the rate that the average saver uses to discount future consumption," for which "the real rate of return on long-term government debt may provide a fair approximation," and from 1973 to 2003, the real rate of return on 10-year U.S. Treasury bonds averaged around $3 \%$.

${ }^{22}$ Nordhaus (2007, p. 692) argues that normative discount rates are "irrelevant" for public policy and that determining the appropriate benchmark for climate investments requires a careful look at "the real real interest rate." We argue that the "real" real interest rate has fallen to a lower new normal.
} 
short-run cycles for currently low real rates. Our empirical models of SDRs are consistent with the models in the macro-finance literature that account for trend shifts in real interest rates. Such results underpin a consensus that the trend component $r_{t}^{*}$ has been a key driver of recent low real interest rates. Once we allow for shifts in this trend component, or long-run mean, the low observed real rates translate into a substantial downward shift in the entire term structure of SDRs. Our results support the use of real discount rates between $0.5 \%$ and $2 \%$ (see Figure 2) and bridge the gap between descriptive and normative SDRs.

A popular theoretical framework used to formulate and analyze SDRs is a simple Ramsey rule that relates the real interest rate $r_{t}$ to the growth rate of consumption $g_{t}$ as follows:

$$
r_{t}=\delta+\eta g_{t}
$$

where $\delta$ is the pure rate of time preference - how impatient society is or should be - and $\eta$ is the elasticity of marginal utility. For example, an influential report by the National Academies of Sciences, Engineering, and Medicine (NAS (2017)) recommends the use of the Ramsey rule for generating discount rates. We show in the Online Appendix that an extended Ramsey rule that allows for uncertainty and for a shifting trend in the growth rate naturally gives rise to time variation in $r_{t}^{*}$. A potentially useful feature of the Ramsey rule is that it explicitly links the growth rate of the economy to the discount rate. Unfortunately, the empirical evidence for a relationship between trend growth and the trend real rate is tenuous at best (Hamilton et al., 2016), as there are many other factors not captured in this simple framework that theoretical and empirical work has shown to affect $r_{t}^{*}$ (Rachel and Summers, 2019). In addition, the Ramsey rule is rooted in a normative approach to the analysis of discount rates that contrasts with the empirical, market-based approach that we and others advocate (Carleton and Greenstone, 2021). For these reasons, there is no simple mapping of our results into the parameters of the Ramsey rule. This is consistent with the survey results of Drupp et al. (2018), which find that most experts do not follow this rule when recommending SDRs. Still, our evidence generally lends support to Ramsey rule recommendations that imply low discount rates due to a combination of a low rate of time preference, low elasticity of marginal utility, and low trend economic growth.

Another policy implication of our work is that the slope of the SDR term structure is negative, so discount rates decline with the time horizon in order to capture the effect of uncertainty on long-term discount rates. This is consistent with previous theoretical and empirical analyses in the literature. Our particular contribution is to quantify how quickly the SDR should decline with the horizon using empirical time series models of interest rate dynamics. While past U.S. policy was based on constant SDRs that are independent of 
the horizon of future costs and benefits, the use of a declining discount rate schedule was recommended by NAS (2017). Other countries, including the U.K. and France, have already employed declining SDRs (see also Cropper et al., 2014).

The main implication of our research for public policy is a substantially lower level and a declining term structure of discount rates for cost-benefit analysis compared to earlier market-based discount rates and much current policy practice. Our results provide support for lowering the discount rate used in the United States to calculate the social cost of carbon described in IWG-SCC. Wagner et al. (2021) call for a review of discount rates in light of recent lower risk-free interest rates. Carleton and Greenstone (2021) propose to use "a discount rate of no higher than 2 percent" (p. 25), based on the balance of evidence from descriptive analysis of financial market trends (including an early version of our analysis). As a consequence, the results of this paper support substantially more stringent carbon pricing and, more generally, a much more ambitious approach to combating climate change, along the lines advocated in the Stern Review.

As the calculations in Section 5 have illustrated, our new evidence on social discount rates implies substantially higher estimates of the social cost of carbon. While our SCC estimates are based on one specific IAM type - the DICE model and its variants - the conclusion that the pronounced decline in the term structure of SDRs leads to a quantitatively large impact on the estimated SCC is likely to generalize to other damage functions. A doubling of the social cost of carbon as a result of updating the SDRs along the lines we propose seems plausible, independent of the exact modeling framework to estimate climate damages and climate-economy feedback effects. As stressed by Carleton and Greenstone (2021), given the recent sizable advances in computing power and access to data, it is possible to use very granular detail on socioeconomic and climatic conditions to provide updated damage estimates with high spatial detail. Other modifications, such as incorporating equity considerations, would cause significant further increases in the SCC. At some point, likely around a level of a few hundred dollars per ton of $\mathrm{CO}_{2}$, the SCC is sufficiently high to justify policies that rapidly reduce GHG emissions to net zero. For a detailed discussion of the issues surrounding such paths of "near-term to net-zero" see Kaufman et al. (2020).

The IWG-SCC also stressed the importance of including global and not just U.S. damages from climate change in calculating a federal SCC. Unlike many domestic cost-benefit calculations, climate change and GHG emissions are a global externality. Indeed, 85\% of the damages from U.S. $\mathrm{CO}_{2}$ emissions are incurred by the rest of the world (Wagner et al., 2021). Therefore, as is standard, our DICE model damages are calculated worldwide. However, this global perspective also appropriately extends to the discount rate. Our empirical analysis uses U.S. data, namely, Treasury yields and price inflation, to quantify the decline in $r_{t}^{*}$. But 
the structural factors underlying the measured drop in $r_{t}^{*}$ in the United States - for example, the shifts in demographics, saving behavior, and productivity - are observed in many other countries as well. Furthermore, given generally low impediments to the cross-border mobility of capital and the global integration of sovereign bond markets (Clarida, 2021), equilibrium real rates in different countries are equalized to a substantial degree by international financial flows. ${ }^{23}$ Several papers have documented a global secular decline in $r_{t}^{*}$ as interest rates have remained persistently low in many countries (Holston et al., 2017; Del Negro et al., 2019). Consequently, while the results in this paper pertain to SDRs based on data from the United States, similar forces and arguments are relevant for many other countries, and our evidence implies that the SDR term structure has likely shifted lower worldwide, with similar implications for the calculation of a SCC with global damages and SDRs.

Also, although our empirical analysis has focused solely on the social cost of carbon, our estimated lower term structure of SDRs is also relevant for social cost calculations for other GHGs. In 2016, the U.S. IWG published estimates for the social costs of methane and nitrous oxide using a similar methodology to the one used for $\mathrm{CO}_{2}$. These other GHGs are more potent than $\mathrm{CO}_{2}$, trapping much more heat for a given amount of gas, but they do not persist in the atmosphere as long. Emitted methane persists for perhaps a dozen years, nitrous oxide for several generations, and $\mathrm{CO}_{2}$ can last for thousands of years. Despite these shorter lifetimes, as shown in IWG-SCC, a lower discount rate can still have a considerable effect in boosting the SCC for these GHGs, so our results likely generalize to these SCC with only a small reduction in the effect of $r_{t}^{*}$.

Finally, we consider how to account for climate risk, that is, how to treat the uncertainty regarding the discounted future damages from changes in GHG emissions. We have focused on expected damages in constructing the SCC and ignored the risk that these damages could be much higher or lower. Specifically, we have used real government bond yields to estimate risk-free social discount rates and a social rate of time preference. Risk-free SDRs have long been a widely-used benchmark for social discounting (e.g., Newell and Pizer, 2003, Groom et al., 2007, and Drupp et al., 2018). As explained in Section 2, they are appropriate to discount future payoffs that are either riskless or have been risk-adjusted and expressed as certainty-equivalent expected payoffs. However, in many cases, uncertain future payoffs will make it necessary to incorporate risk discounting as well as time discounting, so the risk characteristics of future damages help determine the appropriate SDR. Standard asset pricing logic implies that a project is risky if its payoffs are positively correlated with aggregate consumption growth - that is, if the so-called consumption $\beta$ is positive - and discounting

\footnotetext{
${ }^{23}$ To the extent that U.S. interest rates are affected, say, by foreign demand for safe assets, then U.S. yields also incorporate information about the social rate of time preference in other countries.
} 
should then use a rate above the risk-free SDR. Conversely, for a negative $\beta$ project, the discount rate should be below the risk-free rate, as the project provides hedging benefits against future aggregate risks. However, there is no consensus about the risk characteristics of climate change mitigation projects. For example, Dietz et al. (2018) estimate a "climate beta" near one, while Daniel et al. (2019), Giglio et al. (2018), and others argue that it should be negative. ${ }^{24}$ Furthermore, some papers have found that risk and risk aversion have a surprisingly small effect on the SCC. For example, Ackerman et al. (2013) find that a model with climate risk has implications "similar to standard DICE results with the discount rate set to equal the risk-free rate of return." In this case, the SCC would be well estimated using expected damages and risk-free SDRs alone; see also Taconet et al. (2021) and others. The impact of climate risk on the social cost of carbon remains highly uncertain, and research on social discounting has only just begun to appropriately account for it.

Importantly for our purposes, any adjustment for climate risk - regardless of whether $\beta$ is positive or negative - is arguably orthogonal to our contribution. That is, it is unlikely that incorporating a climate risk adjustment would alter our main conclusion that the term structure of SDRs has shifted down significantly in recent decades. Risk-adjusted SDRs are determined by the combination of risk-free SDRs and a climate risk premium. Therefore, undoing our conclusion would require that the secular decline in risk-free rates be offset by a similar-sized increase in the climate risk premium. There is no theoretical support or empirical evidence to suggest that the climate risk premium has increased due to a decline in $r_{t}^{*}$.

Like a sizable portion of the literature, we have used real government bond yields to estimate risk-free SDRs. By contrast, others have obtained descriptive SDRs based on estimates of the economy-wide return on capital (Nordhaus, 1994, 2014). However, this approach appears conceptually problematic from an asset pricing perspective and is fraught with serious measurement problems. ${ }^{25}$ Conceptually, the return on capital is the appropriate discount rate only for projects with risk characteristics exactly like those of the aggregate productive capital stock. The assumption that climate damages possess such risk characteristics seems too strong, as it essentially imposes a climate beta of one. Empirically, the measurement of an economy-wide return is very uncertain, with difficulties, for example, in accounting for separate returns to capital and labor in unincorporated businesses, determining economic depreciation rates, and imputing the intangible capital stock, say, of intellectual property. Economy-wide estimates are usually motivated by historical stock market returns as a proxy

\footnotetext{
${ }^{24} \mathrm{An}$ additional layer of complexity is that each mitigation or adaptation project will have different risk characteristics and a specific consumption $\beta$ and so will require a tailored SDR to appropriately discount its future payoffs.

${ }^{25} \mathrm{Li}$ and Pizer (2018) strongly caution against using the return on capital for long-run discounting.
} 
estimate for the overall return on capital (Weitzman, 2007), although the equity market covers only a limited portion of the aggregate capital stock. Risk premia and economic distortions, including market power and asymmetric information, create a divergence between the rate of return that savers earn and the private rate of return to capital. The sizable wedge between these two returns has also widened considerably in recent decades, at least partly driven by increasing risk premia as well as market power (Caballero et al., 2017; Farhi and Gourio, 2019).

\section{Conclusion}

This paper has argued that the decline in the equilibrium real interest rate over the past three decades has important consequences for the economics of climate change. In particular, the lower new normal in interest rates, which reflects a drop in $r_{t}^{*}$, lowers the entire term structure of discount rates and boosts the social cost of carbon. Quantitatively, our models estimate a decline in $r_{t}^{*}$ of about 1 to 2 percentage points since the 1990s, which results in at least a doubling of the SCC in the United States, using the climate change damages from modern IAMs. The results of our empirical analysis imply that public policy guidance should be revised to use discount rates that are lower than those used in the past and that decline with the horizon. Furthermore, our higher estimates for the SCC support the case for more stringent carbon pricing and, more generally, a more ambitious policy approach to mitigating greenhouse gas emissions and combating climate change - along the lines advocated in the Stern Review.

Our paper is a first step toward incorporating new evidence on the equilibrium real interest rate into the economics of climate change, and more remains to be done. For example, our analysis uses estimates of $r_{t}^{*}$ that do not explicitly take into account the wideranging structural changes caused by climate change that are in train for the economy. As the climate continues to change, there are likely to be associated changes in interest rates and $r_{t}^{*}$. The level of interest rates may decline given the adverse effects of global warming on trend productivity and output growth or increased precautionary savings to protect against climate disasters. In this case, the feedback from climate change to interest rates would tend to strengthen our result that the appropriate interest rate benchmark to use for discounting climate change is lower than what has been observed in the past. More generally, modeling the joint determination of the equilibrium real interest rate, economic growth, and global warming may reveal sizable feedback effects relevant for valuing the consequences of climate change. Despite useful first steps in this direction, as in Hambel et al. (2020) and Dietrich et al. (2021), accounting for the general equilibrium and feedback effects of the climate 
system and interest rates in IAMs remains an important and challenging area for future climate change research.

Another promising direction for future work is to leverage modern tools of financial economics to make better use of the information in market-observed real bond yields. While our analysis, like previous work using market rates, has generally focused on the time series dimension of the data, there is relevant cross-sectional information in, for example, U.S. TIPS yields or U.K. inflation-linked bond yields, that can improve inference about the term structure of discount rates. In addition, government yield curves in other countries should be informative for estimation of long-term SDRs, especially because some countries have issued government bonds with very long maturities.

Perhaps the most pressing open questions in this research area are about the treatment of climate risk. Evidence on risk-free social discount rates can only be a first step in a broader effort to accurately discount future climate change damages. The issue boils down to this central question: "Do we believe that most of the benefits of fighting climate change will materialize when future consumption will be large (for example, because of the large associated level of emissions), or when future consumption will be small?" (Gollier, 2014, p. 537). Given the power of compounding, which becomes strikingly evident from the quantitative effects of changes in discount rates like the ones we have shown, the answer to this question will likely have profound implications for the analysis of climate change damages and the resulting policy implications.

\section{References}

Ackerman, Frank, Elizabeth A. Stanton, and Ramón Bueno (2013) "Epstein-Zin utility in DICE: Is risk aversion irrelevant to climate policy?" Environmental and Resource Economics, 56 (1), 73-84.

Bauer, Michael D. and Glenn D. Rudebusch (2016) "Monetary Policy Expectations at the Zero Lower Bound," Journal of Money, Credit and Banking, 48 (7), 1439-1465.

_ (2020) "Interest Rates Under Falling Stars," American Economic Review, 110 (5), $1316-1354$.

Bernanke, Ben S. (2020) "The new tools of monetary policy," American Economic Review, $110(4), 943-83$.

Beveridge, Stephen and Charles R Nelson (1981) "A new approach to decomposition of 
economic time series into permanent and transitory components with particular attention to measurement of the 'business cycle'," Journal of Monetary Economics, 7 (2), 151-174.

Blanchard, Olivier (2019) "Public debt and low interest rates," American Economic Review, 109 (4), 1197-1229.

Caballero, Ricardo J, Emmanuel Farhi, and Pierre-Olivier Gourinchas (2017) "Rents, technical change, and risk premia accounting for secular trends in interest rates, returns on capital, earning yields, and factor shares," American Economic Review, 107 (5), 614-20.

Campbell, John Y. and Pierre Perron (1991) "Pitfalls and Opportunities: What Macroeconomists Should Know About Unit Roots," NBER Macroeconomics Annual, 6, 141-201.

Carleton, Tamma and Michael Greenstone (2021) "Updating the United States Government's Social Cost of Carbon," Working Paper 2021-04, University of Chicago, Becker Friedman Institute for Economics.

Carvalho, Carlos, Andrea Ferrero, and Fernanda Nechio (2016) "Demographics and Real Interest Rates," European Economic Review, 88, 208-226.

Christensen, Jens H. E. and Glenn D. Rudebusch (2015) "Estimating Shadow-Rate Term Structure Models with Near-Zero Yields," Journal of Financial Econometrics, 13 (2), $226-259$.

(2019) "A New Normal for Interest Rates? Evidence from Inflation-Indexed Debt," Review of Economics and Statistics, 101 (5), 933-949.

Cieslak, Anna and Pavol Povala (2015) "Expected Returns in Treasury Bonds," Review of Financial Studies, 28 (10), 2859-2901.

Clarida, Richard H. (2021) "Sovereign Markets, Global Factors," May, Speech at the 25th Annual Financial Markets Conference of the Federal Reserve Bank of Atlanta.

Cropper, Maureen L., Mark C. Freeman, Ben Groom, and William A. Pizer (2014) "Declining Discount Rates," American Economic Review: Papers and Proceedings, 104 (5), 538-43.

Daniel, Kent D., Robert B. Litterman, and Gernot Wagner (2019) "Declining CO2 price paths," Proceedings of the National Academy of Sciences, 116 (42), 20886-20891.

Del Negro, Marco, Domenico Giannone, Marc P. Giannoni, and Andrea Tambalotti (2017) "Safety, Liquidity, and the Natural Rate of Interest," Brookings Papers on Economic Activity, 2017 (1), 235-316. 
(2019) "Global trends in interest rates," Journal of International Economics, 118, $248-262$.

Dietrich, Alexander, Gernot Müller, and Raphael Schoenle (2021) "The Expectations Channel of Climate Change: Implications for Monetary Policy," CEPR Discussion Paper 15866, Centre for Economic Policy Research.

Dietz, Simon, Christian Gollier, and Louise Kessler (2018) "The climate beta," Journal of Environmental Economics and Management, 87, 258-274.

Dietz, Simon, Rick van der Ploeg, Armon Rezai, and Frank Venmans (2020) "Are economists getting climate dynamics right and does it matter?," Economics Series Working Papers 900, University of Oxford, Department of Economics, https://ideas.repec.org/p/oxf/ wpaper/900.html.

Drupp, Moritz A., Mark C. Freeman, Ben Groom, and Frikk Nesje (2018) "Discounting Disentangled," American Economic Journal: Economic Policy, 10 (4), 109-34, 10.1257/ pol.20160240.

Durbin, James and Siem Jan Koopman (2002) "A Simple and Efficient Simulation Smoother for State Space Time Series Analysis," Biometrika, 89 (3), 603-616.

Farhi, Emmanuel and François Gourio (2019) "Accounting for Macro-Finance Trends: Market Power, Intangibles, and Risk Premia," Brookings Papers on Economic Activity: Fall $2018,147$.

Freeman, Mark C. and Ben Groom (2016) "How certain are we about the certainty-equivalent long term social discount rate?" Journal of Environmental Economics and Management, $79,152-168$.

Freeman, Mark C., Ben Groom, Ekaterini Panopoulou, and Theologos Pantelidis (2015) "Declining discount rates and the Fisher effect: Inflated past, discounted future?" Journal of Environmental Economics and Management, 73, 32-49.

Gagnon, Etienne, Benjamin K Johannsen, and David Lopez-Salido (2021) "Understanding the new normal: The role of demographics," IMF Economic Review, 1-34.

Gerlagh, Reyer, Richard Jaimes, and Ali Motavasseli (2017) "Global Demographic Change and Climate Policies," Working Paper Series 6617, CESifo. 
Giglio, Stefano, Matteo Maggiori, Krishna Rao, Johannes Stroebel, and Andreas Weber (2018) "Climate Change and Long-Run Discount Rates: Evidence from Real Estate," Research Paper 17-22, Chicago Booth School of Business.

Giglio, Stefano, Matteo Maggiori, and Johannes Stroebel (2015) "Very long-run discount rates," The Quarterly Journal of Economics, 130 (1), 1-53.

Gollier, Christian (2002) "Discounting an uncertain future," Journal of Public Economics, 85 (2), 149-166.

(2013) Pricing the planet's future: the economics of discounting in an uncertain world: Princeton University Press.

(2014) "Discounting and growth," American Economic Review: Papers 83 Proceedings, 104 (5), 534-37.

Gollier, Christian, Phoebe Koundouri, and Theologos Pantelidis (2008) "Declining discount rates: Economic justifications and implications for long-run policy," Economic Policy, 23 (56), 758-795.

Greenstone, Michael, Elizabeth Kopits, and Ann Wolverton (2013) "Developing a Social Cost of Carbon for U.S. Regulatory Analysis: A Methodology and Interpretation," Review of Environmental Economics and Policy, 7 (1), 23-46, 10.1093/reep/res015.

Groom, Ben, Phoebe Koundouri, Ekaterini Panopoulou, and Theologos Pantelidis (2007) "Discounting the Distant Future: How Much Does Model Selection Affect the Certainty Equivalent Rate?" Journal of Applied Econometrics, 22 (3), 641-656.

Hambel, Christoph, Holger Kraft, and Rick van der Ploeg (2020) "Asset Diversification versus Climate Action," Discussion Paper 14863, Centre for Economic Policy Research.

Hamilton, James D., Ethan S. Harris, Jan Hatzius, and Kenneth D. West (2016) "The Equilibrium Real Funds Rate: Past, Present, and Future," IMF Economic Review, 64 (4), $660-707$.

Hänsel, Martin C., Moritz A. Drupp, Daniel J.A. Johansson, Frikk Nesje, Christian Azar, Mark C. Freeman, Ben Groom, and Thomas Sterner (2020) "Climate economics support for the UN climate targets," Nature Climate Change, 10 (8), 781-789.

Hepburn, Cameron, Phoebe Koundouri, Ekaterini Panopoulou, and Theologos Pantelidis (2009) "Social discounting under uncertainty: A cross-country comparison," Journal of Environmental Economics and Management, 57 (2), 140-150. 
Holston, Kathryn, Thomas Laubach, and John C. Williams (2017) "Measuring the Natural Rate of Interest: International Trends and Determinants," Journal of International Economics, 108, S59-S75.

Interagency Working Group on Social Cost of Greenhouse Gases (2021) "Social Cost of Carbon, Methane, and Nitrous Oxide. Interim Estimates under Executive Order 13990," technical support document, Unites States Government.

Kaufman, Noah, Alexander R Barron, Wojciech Krawczyk, Peter Marsters, and Haewon McJeon (2020) "A near-term to net zero alternative to the social cost of carbon for setting carbon prices," Nature Climate Change, 10 (11), 1010-1014.

Li, Qingran and William A. Pizer (2018) "The Discount Rate for Public Policy over the Distant Future," Working Paper Series 25413, National Bureau of Economic Research.

Lunsford, Kurt G. and Kenneth D. West (2019) "Some Evidence on Secular Drivers of US Safe Real Rates," American Economic Journal: Macroeconomics, 11 (4), 113-139.

Morley, James C., Charles R. Nelson, and Eric Zivot (2003) "Why are the Beveridge-Nelson and unobserved-components decompositions of GDP so different?" Review of Economics and Statistics, 85 (2), 235-243.

National Academies of Sciences, Engineering, and Medicine (2017) Valuing Climate Damages: Updating Estimation of the Social Cost of Carbon Dioxide, Washington, DC: The National Academies Press.

Newell, Richard G. and William A. Pizer (2003) "Discounting the distant future: how much do uncertain rates increase valuations?" Journal of Environmental Economics and Management, 46 (1), 52-71.

Newell, Richard G., William A. Pizer, and Brian C. Prest (2020) "A Discounting Rule for the Social Cost of Carbon," unpublished manuscript.

Nordhaus, William D. (1994) Managing the Global Commons: MIT Press, Cambridge.

- (2007) "A Review of the Stern Review on the Economics of Climate Change," Journal of Economic Literature, 45 (3), 686-702, 10.1257/jel.45.3.686.

— (2014) A question of balance: Weighing the options on global warming policies: Yale University Press. 
_ (2017) "Revisiting the social cost of carbon," Proceedings of the National Academy of Sciences, 114 (7), 1518-1523.

Orphanides, Athanasios and Min Wei (2012) "Evolving macroeconomic perceptions and the term structure of interest rates," Journal of Economic Dynamics and Control, 36 (2), $239-254$.

Piazzesi, Monika and Martin Schneider (2007) "Equilibrium Yield Curves," in NBER Macroeconomics Annual 2006, Volume 21, 389-472: MIT Press.

Pindyck, Robert S. (2013) "Climate Change Policy: What Do the Models Tell Us?" Journal of Economic Literature, 51 (3), 860-72.

van der Ploeg, Frederick and Armon Rezai (2019) "The agnostic's response to climate deniers: Price carbon!," European Economic Review, 111, 70-84.

Rachel, Lukasz and Lawrence H. Summers (2019) "On Secular Stagnation in the Industrialized World," Brookings Papers on Economic Activity.

Schmelzing, Paul (2020) "Eight centuries of global real interest rates, $\mathrm{r}-\mathrm{g}$, and the 'suprasecular' decline, 1311-2018," Staff Working Paper 845, Bank of England.

Stern, Nicholas H. (2007) The Economics of Climate Change: the Stern Review: Cambridge University Press.

Summers, Lawrence H. (2014) "U.S. Economic Prospects: Secular Stagnation, Hysteresis, and the Zero Lower Bound," Business Economics, 49 (2), 65-73.

Taconet, Nicolas, Céline Guivarch, and Antonin Pottier (2021) "Social Cost of Carbon Under Stochastic Tipping Points," Environmental and Resource Economics, 78 (4), 709-737.

U.S. Office of Management and Budget (2003) "Circular A-4," September, https:// obamawhitehouse. archives.gov/omb/circulars_a004_a-4/.

Wagner, Gernot, David Anthoff, Maureen Cropper, Simon Dietz, Kenneth T Gillingham, Ben Groom, J Paul Kelleher, Frances C Moore, and James H Stock (2021) "Eight priorities for calculating the social cost of carbon," Nature, 590, 548-550.

Watson, Mark W. (1986) "Univariate Detrending Methods with Stochastic Trends," Journal of Monetary Economics, 18 (1), 49-75. 
Weitzman, Martin L. (1998) "Why the Far-Distant Future Should Be Discounted at Its Lowest Possible Rate," Journal of Environmental Economics and Management, 36 (3), 201-208, 10.1006/jeem.1998.1052.

(2001) "Gamma Discounting," American Economic Review, 91 (1), 260-271, 10. 1257/aer.91.1.260.

(2007) "A Review of the Stern Review on the Economics of Climate Change," Journal of Economic Literature, 45 (3), 703-724, 10.1257/jel.45.3.703. 